\title{
The Role of Learning Styles in the Evolving Landscape of Medical Education: the Canadian Plastic Surgery Experience
}

\author{
Kaitlin S. Boehm, Connor McGuire, Osama A. Samargandi, David T. Tang \\ Division of Plastic Surgery, Dalhousie University, Halifax, Nova Scotia, Canada
}

ABSTRACT

Objective: The transition to competency-based medical education and restraints on trainee work hours necessitates re-evaluation of resident education. As is the case in many programs, the role of learning style in plastic surgery residency training has not yet been investigated. The objective of this study is to identify the learning styles of plastic surgeons and trainees in Canadian Plastic Surgery programs.

Methods: A cross-sectional electronic survey was distributed to all members of the Canadian Society of Plastic Surgeons. Basic demographics were captured. Further, the Kolb Learning Style Inventory was used to identify each individual's learning style as either converging, accommodative, assimilative, or divergent.

Results: There were a total of 98 respondents (15\% response rate), including 62 staff plastic surgeons (63\%) and 36 trainees (37\%). All regions of Canada and age categories were well represented. The most dominant learning styles were convergent (47\%) and accommodative (29\%). No significant difference in dominant learning styles existed between age groups; while males were more commonly convergent learners, females were more likely to be accommodative learners.

Conclusion: The majority of plastic surgery trainees and staff have learning styles that rely heavily on practical application and experiential learning. Accounting for this propensity towards convergent and accommodative learning styles should be incorporated into training programs to maximize efficacy of learning.

\section{RÉSUMÉ}

Objectifs: La transition vers une éducation médicale basée sur les compétences et les contraintes sur les heures de travail des stagiaires nécessite une réévaluation de la formation des résidents. Comme dans de nombreux programmes, le rôle du style d'apprentissage dans la formation au niveau de résidence en chirurgie plastique n'a pas encore été étudié. L'objectif de cette étude est d'identifier les styles d'apprentissage des chirurgiens plasticiens et des stagiaires dans les programmes canadiens en chirurgie plastique.

Méthodes: Un sondage électronique transversal a été distribué à tous les membres de la Société Canadienne des Chirurgiens Plasticiens. Les données démographiques de base ont été recueillies. De plus, l'inventaire des styles d'apprentissage de Kolb a été utilisé pour identifier le style d'apprentissage de chaque individu en tant que convergent, accommodateur, assimilateur ou divergent.

Résultats: Au total, 98 personnes ont répondu (taux de réponse de 15\%), dont 62 chirurgiens plasticiens (63\%) et 36 stagiaires (37\%). Toutes les régions du Canada et toutes les catégories d'âge étaient bien représentées. Les styles d'apprentissage les plus dominants étaient convergent (47\%) et accommodateur (29\%). Aucune différence significative dans les styles d'apprentissage dominants n'existait entre les groupes d'âge; tandis que les hommes étaient plus généralement des apprenants convergents, les femmes étaient plus susceptibles d'être des apprenantes accommodatrices.

Conclusion: La majorité des stagiaires et du personnel en chirurgie plastique ont des styles d'apprentissage qui reposent largement sur l'application pratique et un apprentissage par expérience. La prise en compte de cette propension à adopter des styles d'apprentissage convergents et accommodateurs devrait être intégrée aux programmes de formation afin de maximiser l'efficacité de l'apprentissage.

Keywords: Learning style, Medical education; Experiential learning; Kolb Learning Styles 


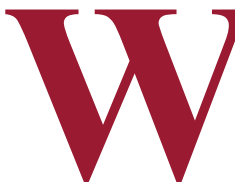

ith all Canadian residency programs transitioning to competency-based medical education (CBME) by 2022, stricter enforcement of work hour regulations, increasing knowledge expected of trainees and Royal College examinations being moved earlier in training, it is ever more important to re-evaluate and optimize the delivery of resident education to ensure learners have acquired the required knowledge in less time (1-6). How learners internalize information through their learning style influences their knowledge and skill acquisition (5, 7-9). Therefore, tailoring the curriculum to the predominant resident learning styles can maximize the efficiency and efficacy of educational delivery $(5,9)$.

The Kolb Learning Style Inventory (LSI) was first proposed in 1984 and is a validated method to help identify how people learn (10). Its application in medicine and other disciplines has allowed for international refinement and improvement of educational delivery methods (2). The Kolb LSI categorizes individuals into one of four styles: convergent, accommodative, assimilative, or divergent (Figure 1). Convergers are problem solvers who use practical application and deductive reasoning and tend to prefer technical tasks. Accommodators are experientially driven, learning through action and experimentation. They rely on the analysis of others, and act on instinct. Assimilators prefer clear explanations and theoretical knowledge and are adept at organizing wideranging information into logical and concise ideas. Divergers view problems from multiple perspectives, solve problems through brainstorming use brainstorming to solve problems and prefer observation to action $(1,6,9)$.

Research using this inventory in medicine has shown that learning styles vary considerably between specialties, residency programs, and years of medical training (1, 4, 11-13). Disciplines of medicine tend to cluster towards certain leaning styles. For example, Internal Medicine is typically dominated by assimilative learning style, while surgical residents are more likely to be convergent learners (1). Currently, research is sparse surrounding the specific learning styles of plastic surgery trainees and attending surgeons.

The objective of this study was to identify the learning styles of plastic surgery trainees and attending physicians in Canadian Plastic Surgery programs. Understanding the learning style of residents and staff will give program directors and curriculum designers valuable guidance to help optimize education delivery during curriculum redesign in accordance with CBME. The implementation of rituximab in chemotherapy protocols has also been studied in pediatric Burkitt's lymphoma populations and a recent randomized controlled trial showed favourable results (13). This international study randomized 600 patients with high-risk B cell non-Hodgkin's lymphoma to standard Lymphome Malins de Burkitt (LMB) chemotherapy with or without the addition of rituximab. A planned interim analysis including 310 randomized patients, of which $85 \%$ had Burkitt's lymphoma, showed a 1-year event-free survival rate of $94 \%$ in the rituximab group, compared to $81 \%$ in the standard chemotherapy group. This finding led to an early closure of the study as the rituximab arm had significantly improved outcomes, confirming that this drug's efficacy also extends to the pediatric population.

\section{MATERIALS AND METHODS}

A web-based anonymous survey was distributed between November 2016 and February 2017 to 667 attending surgeons and trainees (residents and fellows) who are current members of the Canadian Society of Plastic Surgeons. Study rationale, participant eligibility and informed consent were outlined in a recruitment letter. Participant demographics included sex, age, region, and year of residency or years in practice. The regions were defined as Atlantic (New Brunswick, Prince Edward Island, Newfoundland and Nova Scotia), Central (Quebec, Ontario), and Western (Manitoba, Albtera, British Columbia). The electronic survey was developed using the existing validated Kolb Learning Style Inventory (9). Following completion of the survey, each participant received a description of their individual learning style.

Data was exported to a Microsoft Excel (Microsoft ${ }^{\oplus}$ v. 14.5.6, Redmond, Washington) data sheet that was prepared a priori. Univariate descriptive analysis was performed for all variables and bivariate analysis was also completed. The survey was distributed using Opinio Survey Software (Object Planet, Oslo, Norway). SPSS version 24 was used for all statistical analyses (IBM SPSS Statistics, Armonk, NY, USA). This project received institutional ethical approval by the Dalhousie University Research Ethics Board (File No. 2016-3914).

\section{RESULTS}

\section{Demographics}

A total of 98 plastic surgeons and trainees responded, with an overall response rate of $15 \%$. Demographic characteristics are detailed in Table 1. Of the respondents, 62 were attending plastic surgeons $(63 \%)$ and 36 were trainees (37\%). Sixty five 
percent of respondents were male. There was representation from all regions (Atlantic, Central, Western) and age categories (20-70 years), with approximately $70 \%$ of respondents below the age of 50 . Respondents in training and early practice (2640 years) accounted for approximately half of respondents (52\%).

Table 1. Demographic characteristics of Canadian plastic surgery staff and trainees responding to a learning based survey $(\mathrm{N}=98)$.

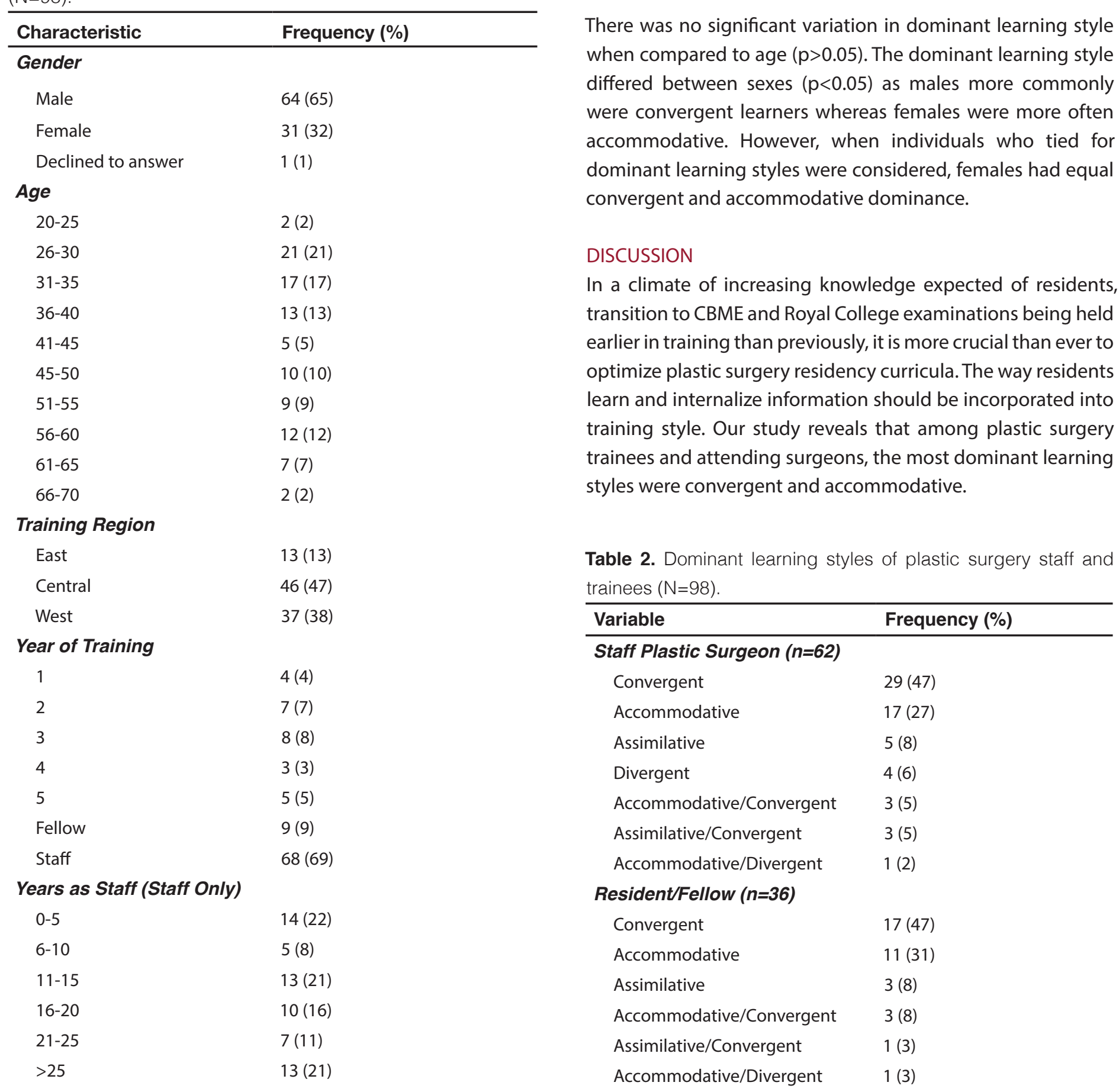

\section{Learning style}

Table 2 and Figure 2 detail the dominant learning styles of both trainees and staff. The overall dominant learning style was convergent (47\%) followed by accommodative (28\%), which was consistent when comparing learning styles between trainees and attending surgeons. This calculation does not include 12 participants who had a tie between two dominant learning styles. The least common learning style was divergent (4\%).

There was no significant variation in dominant learning style differed between sexes $(p<0.05)$ as males more commonly

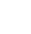


To optimize the likelihood of knowledge retention, residency programs should aspire to create curriculums that are tailored to the way their residents learn (7). Similar to other surgical specialties, this study demonstrated a predominance for convergent and accommodative learning styles among residents $(1,2,4-6)$. With this knowledge, utilizing teaching strategies that play to the strengths of these learning styles will improve learning. Additionally, implementing Kolb LSI assessments within training programs will identify group learning dynamics and provide attendings with the ability to understand a trainee's preferred learning method (14). In cost-conscious training programs, understanding the learning dynamics of the group can guide the selection of the most appropriate and ultimately cost-effective means of curriculum delivery. For example, regular integration of experiential learning may favour lasting knowledge retention and technical skill development in surgical trainees (15-17). Practical examples of experiential learning include case-based or problem-based scenarios, videos, practical simulation, cadaver or model-based skills labs, and practice oral examinations. Table 3 illustrates teaching strategies that are best matched to learning style, which demonstrates what didactic lectures can most effectively be replaced or augmented with. Within the CBD framework, integrating simulation and/or cadaver labs into surgical residency curricula could also potentially be used to help residents achieve required Entrustable Professional
Table 3. Methods of teaching that best compliment the four Kolb learning styles.

\begin{tabular}{lll}
\hline $\begin{array}{l}\text { Kolb Learning } \\
\text { Style }\end{array}$ & Characteristics & $\begin{array}{l}\text { Teaching Strategies } \\
\text { To Compliment } \\
\text { Learning Style }\end{array}$ \\
\hline Converging & - Problem-solver & -Assessing clinical \\
& - Practical & literature \\
& - Deductive reasoning & - Oral examinations \\
& - Prefer technical tasks & - Case presentations \\
& & - Simulation \\
& & \\
\hline Accommodating & - Learn from & - Simulation \\
& experience and & - Cadavers/models \\
& experimentation & - Problem-based \\
& - Instinctual & learning \\
\hline Assimilating & - Rely on theoretical & - Simulation \\
& knowledge & - Problem-based \\
& - Information & learning \\
& organization and & - Textbook learning \\
& categorizing & \\
\hline - Logic & - Learn by observation & - Simulation \\
& and reflection & - Group work \\
& - Brainstorm & - Directed feedback \\
\hline Diverging & & \\
& & \\
& & \\
& & \\
& & \\
& & \\
& & \\
& & \\
& & \\
& & \\
& & \\
& &
\end{tabular}

Concrete

Experience

ACCOMODATING

Active

Experimentation
DIVERGING

Reflective

Observation

\section{CONVERGING}

Figure 1. Kolb learning style model. 

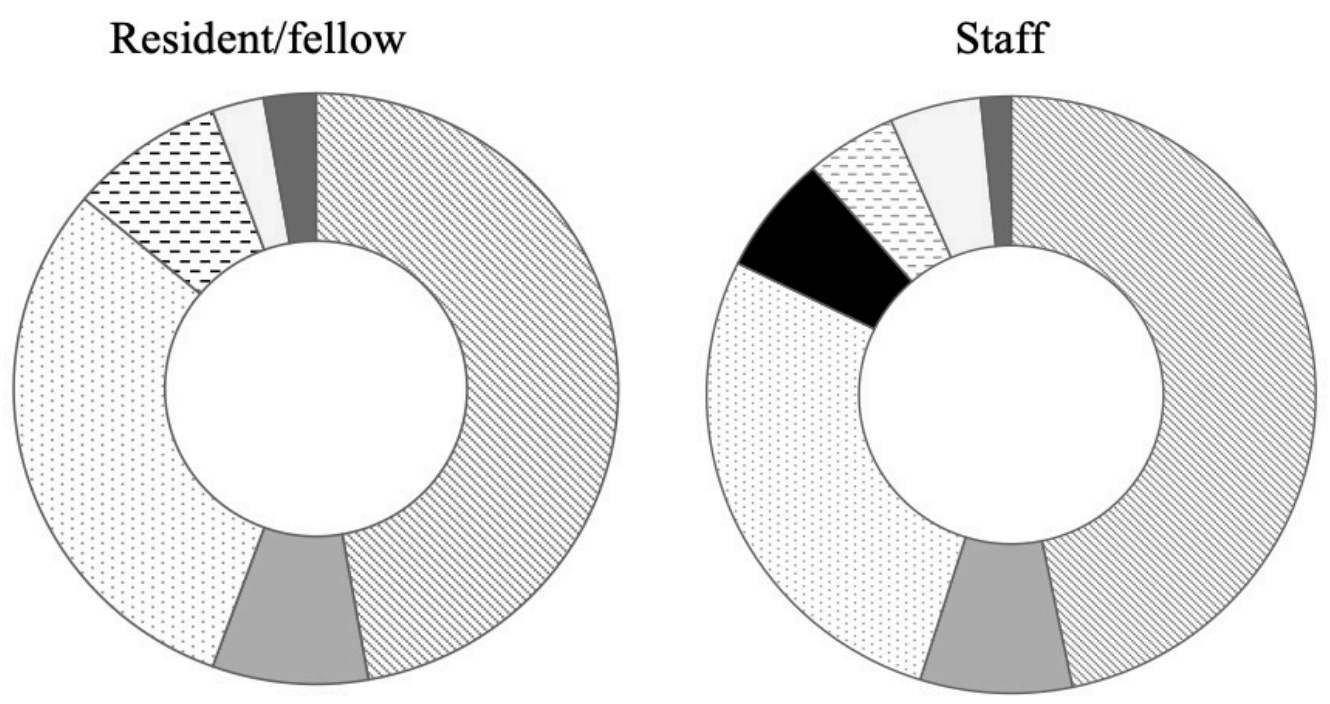

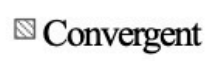

$\square$ Assimilative

Accomodative

Divergent

$\because$ Accomodative/Convergent

$\square$ Assimilative/Convergent

Accomodative/Divergent

Figure 2. Learning styles of Canadian plastic surgery staff and trainees responding to a learning based survey ( $\mathrm{N}=98)$.

Activities. Divergence from traditional didactic instruction can be seen beyond residency education. Teaching through videos, most preferred by convergent and accommodative learners, has been increasingly incorporated into academic journals and articles (18). Transitioning to teaching strategies that reflect trainee learning styles will likely prove a more efficient investment of time and energy than a heavily didactic curriculum. Several studies have looked at these instruction methods in medical and surgical residency training and found favorable results $(15,16)$. These studies showed that integration of practical learning improves initial performance as well as long-term skill retention compared to traditional didactic sessions (15-16). Teaching to trainee learning style may require additional training for existing surgeons. This could be accomplished either as its own workshop or integrated into weekly Divisional rounds presented to both faculty and residents in an effort to build a current and future culture of optimized teaching. Furthermore, since past (attending surgeons) and present trainees share convergent and accommodative learning styles, curriculums incorporating practical learning will likely be effective in future generations of learners.

Review of the literature reveals that no studies that specifically assess the role of dominant learning style in plastic surgery training exist. Research in other disciplines, however, has shown similar results to our study. Similar investigations of general and orthopedic learning styles found that medical school applicants, residents, and attending surgeons most commonly had a convergent learning style $(4,6,12,23)$. The same was found among neurosurgical residents. Interestingly, however, neurosurgical staff physicians showed a stronger preference towards assimilative learning compared to trainees (14). The authors surmised that this may be due to staff having a more mature process of learning, by which they compare new learning in the context of previous successes and failures (14). Regardless of surgical specialty, it is clear that the dominant style of learning is convergent from trainees to surgeons. However, this does not mean that the remaining trainees with divergent or assimilative learning styles should be forgotten. Providing reading resources ahead of experiential learning opportunities followed by group discussions reviewing learning points, tips, and unexpected difficulties after the exercise will similarly favour knowledge retention in divergent and assimilative learners.

A potential new avenue of education delivery that is expected to complement the predominate surgical learning styles is the use of virtual reality (20-22). The American College of Surgeons has recently implemented an approach to general surgery training through computer-based simulations in three phases: skill training, procedure training, and team training (20). While the same approach, to the best of our knowledge, has not been implemented in plastic surgery training, it is an area worth investigating. When relating virtual reality training to learning style, convergent and accommodative learners would benefit substantially from virtual reality training because it complements their ability to improve through abstract comprehension and learned experiences (23). While virtual reality poses a potential role in surgical residency training, the literature has not fully elucidated its benefits (24). Future studies investigating the role of virtual reality training 
in plastic surgery training should incorporate learning style as a variable of comparison.

Upon careful review, our study does have some limitations. The response rate of $15 \%$ is low by survey standards. Despite this, our survey was able to capture data from all training programs across Canada with a wide variation in both age, sex and level of training. This leads us to believe that our results can still be generalized despite the low response rate. As we examined only plastic surgery trainees and attending surgeons in Canada, our results are not generalizable to other surgical specialties or other countries. However, our results do echo those found in studies in other disciplines. Utilization of the Kolb LSI is also limited by the inherent limitations of the model including, primarily, that some people may not neatly fit in one of the four learning styles. In our study we found that a minority of respondents had equally dominant learning styles.

\section{CONCLUSION}

The current state of residency curriculum re-design that will occur in preparation for CBME offers and necessitates the opportunity for optimizing post-graduate medical education. Currently, $75 \%$ of plastic surgery trainees and staff have learning styles that rely heavily on practical application and experiential learning. Teaching methods that are tailored to these learning styles should be incorporated to improve knowledge acquisition and cost efficiency. Further research is needed to explore new educational methods that are suited to these learning styles.

\section{REFERENCES}

1. Contessa J, Ciardiello KA, Perlman S. Surgery resident learning styles and academic achievement. Cur Surg. 2005; 62(3):344-347.

2. Drew PJ, Cule N, Gough M, et al. Optimal education techniques for basic surgical trainees: Lessons from education theory. J Royal Coll Surg Edinburgh. 1999; 44(1):55-56.

3. Kim RH, Gilbert T, Ristig K. The effect of surgical resident learning style preferences on american board of surgery in-training examination scores. J Surg Ed. 2015; 72(4):726-731.

4. Mammen JMV, Fischer DR, Anderson A, et al. Learning styles vary among general surgery residents: Analysis of 12 years of data. J Surg Ed. 2007; 64(6):386-389.

5. Quillin RC, Cortez AR, Pritts TA, Hanseman DJ, Edwards MJ, Davis BR. Surgical resident learning styles have changed with work hours. J Surg Res. 2015; 200(1):39-45.

6. Richard RD, Deegan BF, Klena JC. The learning styles of orthopedic residents, faculty, and applicants at an academic program. J Surg Ed. 2014; 71(1):110-118.

7. Reznick RK, MacRae H. Teaching surgical skills - Changes in the wind. N Engl J Med. 2006; 355(25):2664-2669.

8. Kissane-Lee NA, Yule S, Pozner CN, Smink DS. Attending Surgeons' Leadership Style in the Operating Room: Comparing Junior Residents' Experiences and Preferences. J Surg Ed. 2016; 73(1):40-44.

9. Kayes DC. Internal validity and reliability of Kolb's learning style inventory version 3 (1999). J Bus Psychol. 2005; 20(2):249-257.

10. Kolb DA. Experiential learning: Experience as the source of learning and development. New Jersey: Prentice Hall.

11. Adesunloye BA, Aladesanmi O, Henriques-Forsythe M, Ivonye C. The preferred learning style among residents and faculty members of an internal medicine residency program. J Nat Med Assc. 2008; 100(2):172 177.

12. Engels PT, de Gara C. Learning styles of medical students, general surgery residents, and general surgeons: Implications for surgical education. BMC Med Ed. 2010; 10:51.

13. Linn BS, Cohen J, Wirch J, Pratt T, Zeppa R. The relationship of interest in surgery to learning stydles, grades, and residency choice. Soc Scien Med. 1979; 13:597-600.

14. Jack MC, Kenkare SB, Saville BR, et al. Improving education under workhour restrictions: Comparing learning and teaching preferences of faculty, residents, and students. J Surg Ed. 2010; 67(5):290-296.

15. Ramsingh D, Alexander B, Le K, Williams W, Canales C, Cannesson M. Comparison of the didactic lecture with the simulation/model approach for the teaching of a novel perioperative ultrasound curriculum to anesthesiology residents. J Clin Anest. 2014; 26(6):443-454.

16. Picard M, Curry N, Collins H, Soma L, Hill J. Comparison of High-Fidelity Simulation Versus Didactic Instruction as a Reinforcement Intervention in a Comprehensive Curriculum for Radiology Trainees in Learning Contrast Reaction Management: Does It Matter How We Refresh? Acad Rad. 2015; 22(10):1268-1276.

17. Saraswat A, Bach J, Watson WD, Elliott JO, Dominguez EP. A pilot study examining experiential learning vs didactic education of abdominal compartment syndrome. Am J Surg. 2017; 214(2):358-364.

18. Boehm KS, Rohrich R, Lalonde DH. Why videos matter so much in plastic surgery today: A complete index of videos in plastic and resonctructive surgery and plastic and reconstructive surgery global open. Plast Recon Surg. 2018; 141(4):1051-1054.

19. Caulley L, Wadey V, Freeman R. Learning styles of first-year orthopedic surgical residents at one accredited institution. J Surg Ed. 2012; 69(2):196200.

20. Rosen J, Long SA, McGrath DM, Greer S. Simulation in palstic surgery training and education: The path forward. Plast Recon Surg. 2009; 123(2):729-738.

21. Gorman PJ, Meier AH, Krummel TM. Computer-assisted training and learning in surgery. Comp Aided Surg. 2000; 5(2):120-130.

22. Lee EAL, Wong KW, Fung CC. How does virtual reality enhance learning outcomes? A structural equation modeling approach. Comp Ed. 2010; 55(4):1424-1442.

23. Chen JC, Toh SC, Ismail W. Are learning styles relevant to virtual reality? J Res Tech Ed. 2005; 38(2):123-141.

24. Kneebone R. Simulation in surgical training: Educational issues and practical implications. Med Ed. 2003; 37(3):267-277. 